\title{
Kajian Injection locking Untuk Pengurangan Pengaruh Derau Fasa Pada Osilator CMOS
}

\author{
Ceri Ahendyarti, Prapto Nugroho, Risanuri Hidayat \\ Jurusan Teknik Elektro dan Teknologi Informasi Universitas Gadjah Mada
}

Jalan Grafika 2, Yogyakarta 55281

ceri.ahendyarti.sie13@mail.ugm.ac.id

\begin{abstract}
Abstrak
Kebutuhan telekomunikasi yang meningkat dengan daya rendah dan kinerja yang cepat dan biaya pembuatan yang murah tentunya membuat tantangan tersendiri bagi para peneliti untuk membuatnya. Osilator cincin adalah pilihan yang tepat jika diterapkan pada teknologi CMOS, tetapi tingginya derau fasa yang bisa merusak sinyal keluaran yang diinginkan. Hal ini merupakan tantangan untuk para peneliti untuk membuat derau fasa yang semakin rendah. Makalah ini mendiskusikan tentang salah satu cara mengurangi derau fasa pada osilator yaitu dengan injection locking (penguncian suntikan).
\end{abstract}

Kata Kunci: injection locking, ring oscillator, phase noise

\section{Pendahuluan}

Komunikasi adalah hal yang sangat penting dalam hidup ini. Tanpa adanya alat komunikasi kita akan sangat kesulitan untuk berkomunikasi untuk kepentingan tertentu. Dari waktu ke waktu alat komunikasi sangat berkembang pesat di dunia elektronis. Alat komunikasi dahulu yang masih menggunakan kabel telah lama ditinggalkan karena kehadiran teknologi wireless. Komunikasi jarak dekat seperti Bluetooth ato WLAN (Wireless Local Area Network yang telah menggantikan teknologi komunikasi dengan kabel yang sangat lama [1]-[8].

Osilator adalah komponen dasar dari sistem komunikasi. Dan osilator juga komponen penting yang selalu ada pada blok rangkaian alat telekomunikasi seperti phase-locked loop (PLL) yang digunakan dalam frequency synthesizer dalam blok rangkaian pemancar penerima di sistem telekomunikasi nirkabel Osilator juga digunakan sebagai pembangkit detak (clock) dalam sistem komputer [9]. Skema pemancar penerima nirkabel yang umum digunakan di tunjukkan oleh Gambar 1. 30 tahun yang lalu kebanyakan orang memilih Colpitts Oscilators untuk kebutuhan frekuensi tinggi yaitu pada range megahertz $(\mathrm{MHz})$ dan bipolar junction transistor (BJT) bekerja untuk perangkat aktif. Baru baru ini perkembangan komunikasi wireless dan kemajuan pada teknologi Complementary Metal Oxide Semiconductor (CMOS) memungkinkan untuk mengimplementasikan frekuensi tinggi pada teknologi CMOS [9].

Perkembangan teknologi telekomunikasi nirkabel ini juga telah meningkatkan jumlah slot kanal frekuensi pada aplikasi telepon selular. Hal ini membuat jarak antar frekuensi menjadi semakin kecil sehingga diperlukan osilator dengan phase noise (derau fase) yang makin kecil. Demikian juga dalam perkembangan sistem komputer dimana kecepatan detak menjadi semakin tinggi, maka diperlukan osilator dengan timing jitter yang sangat kecil. Phase noise dan jitter adalah istilah yang berhubungan dengan stabilitas osilator dimana phase noise mendeskripsikan stabilitas dalam kawasan frekuensi sedangkan jitter dalam kawasan waktu. Dalam tulisan ini digunakan istilah phase noise.

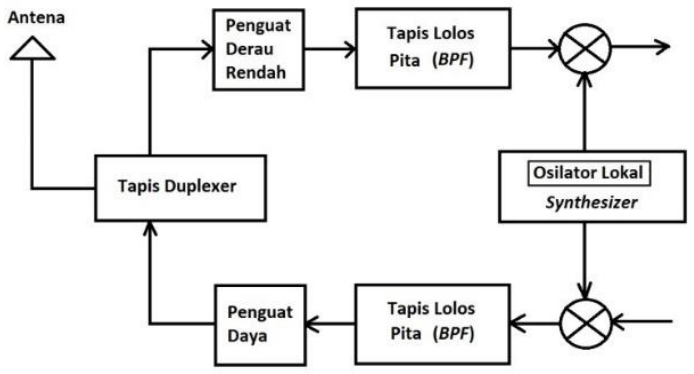

Gambar 1. skema pemancar penerima nirkabel yang umum digunakan

Guna mengurangi derau fasa banyak cara yang bisa dilakukan salah satunya dengan injection locking (penguncian suntikan). Injection locking ini adalah Penekanan pada fase-noise merupakan salah satu sifat penting dari osilator injeksi-clock [10]. Pada kajian ini akan dibahas sesi 1. Pendahuluan 2. Rangkaian Osilator khususnya Ring Oscillator (osilator cincin), session 3. Derau fasa (phase noise) dan sesi 4 injection locking (penguncian suntikan) dan yang terakhir sesi 5 adalah kesimpulan kajian.

\section{Rangkaian Osilator}

Osilator adalah bagian keseluruhan yang penting dari banyak sistem elektronik. Pemakaian atau aplikasinya mempunyai rentang yang luas mulai dari generasi detak pada mikroprosesor 
untuk carrier synthesize pada telepon seluler kebutuhan proses yang semakin cepat, perbedaan topologi dan parameter kinerja yang dibutuhkan. Perancangannya yang diaplikasikan pada teknologi CMOS (Complementary Metal Oxide Semiconductor) yang menambah tantangan untuk membuat yang lebih baik dari segi kecepatan, topologi dan ukuran [11].

Osilator mempunyai beebrapa macam bentuknya namun pada teknologi CMOS yang sekarang secara khas diimplementasikan adalah osilator cincin dan osilator LC.

Osilator cincin adalah osilator tanpa induktor yang dihubungkan dengan koneksi cincin. Osilator ini tidak digunakan secara luas dalam aplikasi frekuensi radio karena memiliki phase noise yang lebih tinggi dibandingkan osilator LC. Akan tetapi, osilator ini dapat diintegrasikan dalam sebuah chip dengan mudah dan tidak memakan tempat sebagaimana osilator LC, sehingga memungkinkan untuk membuat chip yang kecil dan lebih murah. Osilator ring juga mempunyai karakteristik rentang tala yang lebar dan mampu membangkitkan sinyal keluaran quadrature tanpa memerlukan rangkaian tambahan [9], [11]-[14].

Oleh karena itu ring oscillator sering diaplikasikan pada teknologi CMOS. Gambar 2 menunjukkan osilator ring dengan jumlah $\mathrm{N}$ amplifier stage.

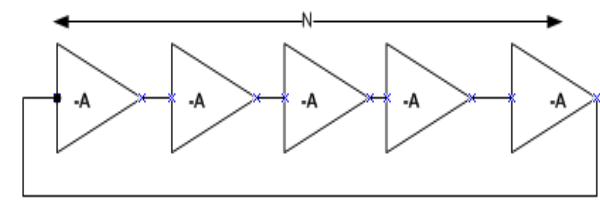

Gambar 2. osilator ring dengan jumlah $\mathrm{n}$ amplifier stage

\section{Phase Noise (Derau Fasa)}

Derau fasa secara umum dikaraktristikkan pada kawasan frekuensi. Osilator yang ideal beroperasi pada $\omega_{0}$, spektrum mengasumsikan bentuk dari impuls, dimana actual osilator, spektrum memaerkan skirts disekeliling atau pusat dari frekuensi carrier.

Satu hal yang penting diketahui dari derau fasa adalah, jika receiver berisi low noise amplifier, band pass filter dan sebagainya yang ditunjukkan pada Gambar 3, jika osilator lokal keluaran berisi phase noise dan keduanya upconverted dan down converted sinyal akan rusak [13].
IDEAL

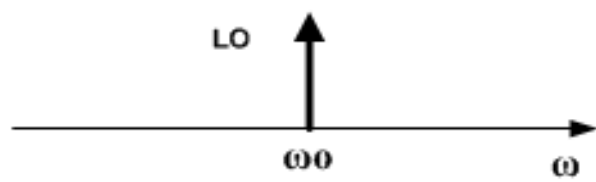

ACTUAL

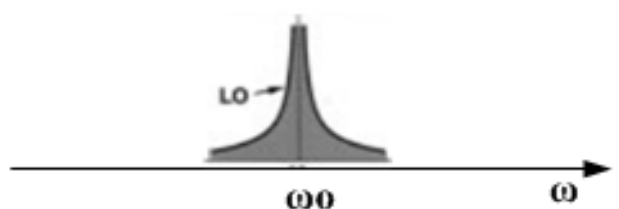

Gambar 3. osilator ideal dan osilator yang ada sebenarnya terdapat derau

Efek dari derau fasa pada jalur pengirim atau (transmitter) sedikit berbeda. Andaikan penerima tidak berderau akan mendeteksi sinyal yang lemah pada $\omega_{2}$ ketika energi penuh, daerah dekat transmitter membuat menghasilkan sinyal pada $\omega_{1}$ dengan derau fasa subtantial. Kemudian sinyal yang diinginkan atau sinyal keluaran akan rusak atau korup oleh derau fasa pada ujung transmitter (pengirim). Seperti kebutuhan yang penting bisa bertemu melalui kegunaan osilator LC. Gambar 4(a) menunjukkan sinyal ketika ada derau, sedangkan Gambar 4(b) menunjukkan sinyal dengan derau.

\section{$4 \quad$ Injection Locking (Suntikan Pengunci)}

Injection locking dengan sumber derau rendah dapat mengurangi derau fasa pada osilator. Dari perspektif kawasan waktu, efek dari pensikronan dari isi injection sendiri sebagai koreksi dari zero crossing dari osilator disetiap periodenya, dengan cara demikian merendahkan akumulasi dari jitter. Pemaparan ini bisa mengungkapkan tentang pengurangan derau fasa sesuai dengan level injection, dan ini bisa mencapai maksimum untuk $\omega_{i n j}=\omega_{o}$ (pada Gambar 5 (a) dimana pada zero crossings dari $\boldsymbol{I}_{i n j}$ sangat berpengaruh pada $\boldsymbol{I}_{o s c}$ ) dan minimum untuk $\omega_{i n j}=\omega_{o} \pm \omega_{L}$ (pada Gambar $5 \mathrm{~b}$ dimana crossing zero dari $\boldsymbol{I}_{i n j}$ bertepatan dengan titik zero-slope pada $I_{o s c}[14]$. 
Seminar Nasional Instrumentasi, Kontrol dan Otomasi (SNIKO) 2015 Bandung, Indonesia, 10-11 Desember 2015

IDEAL
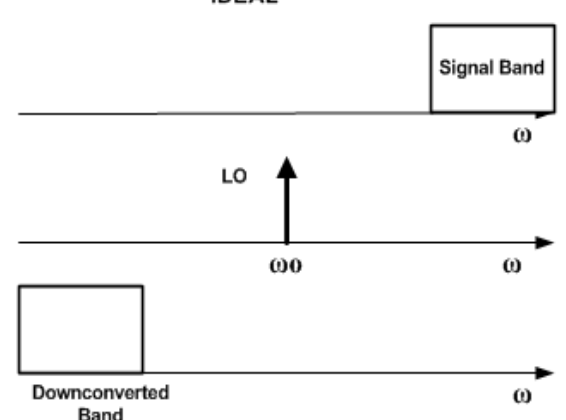

Band

ACTUAL

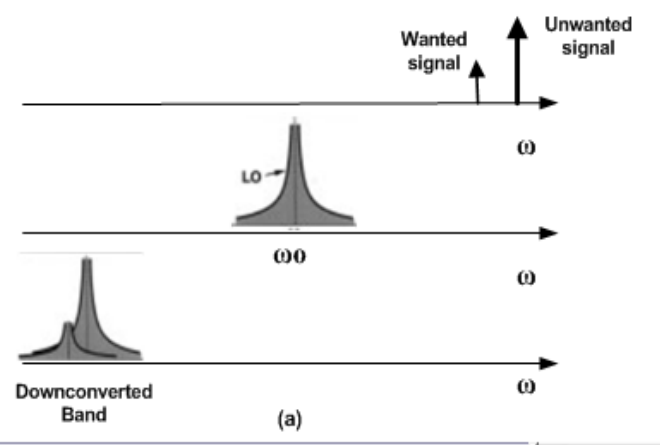

Gambar 4(a). sinyal ketika ada derau

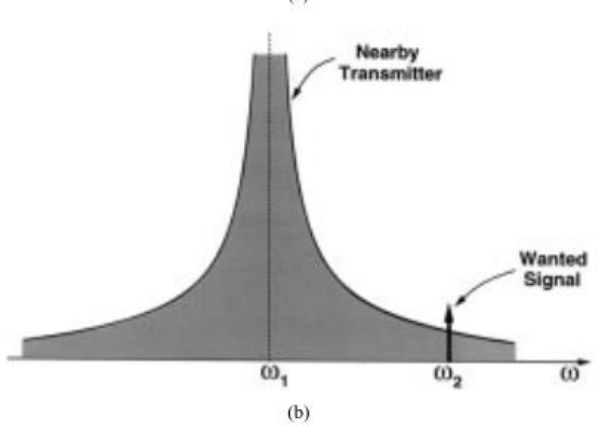

Gambar 4(b). sinyal dengan derau

Phase noise atau derau fasa pada rangkaian teknologi CMOS sulit sekali untuk menyampaikan atau menunjukkan pengurangan derau fasa pada proses injection locking. Karena sejak rentang penguncian secara khas adalah cukup kecil dan frekuensi alami dari osilator dapat menimbulkan error yang signifikan pada proses variai atau besar dan pemodelan yang masih kurang dan sedikit, apalgi bila terjadi penguncian hanya pada pinggiran dari rentang penguncian (lock range), dengan demikian pengurangan derau fasa hanya sedikit sekali.

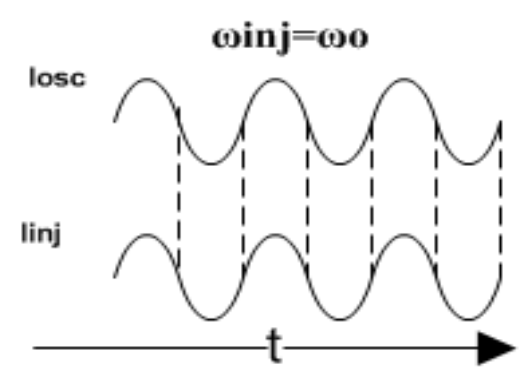

(a)

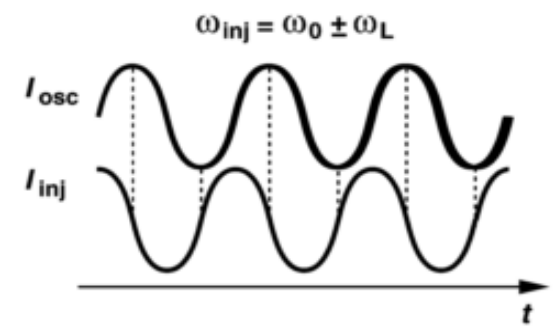

(b)

Gambar 5. secara konsep sinyal osilator dan sinyal setelah diberi injection locking

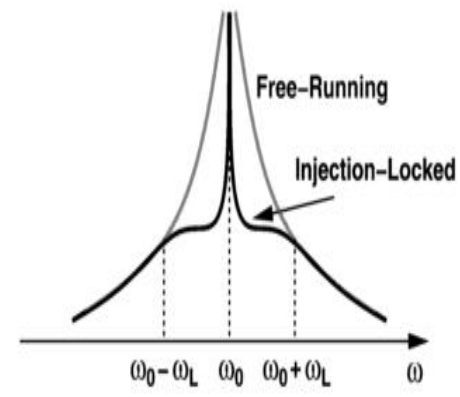

Gambar 6. pengurangan derau fasa karena pengaruh injection locking [14]

Pada percobaan yang dilakukan oleh behzard razavi memberikan level injeksi level kurang lebih 53dB dibawah level osilasi. Dan sideband menjadi simetris karena loop tertutup.yang ditunjukkan oleh gambar 7(a).yaitu gmbar sebelum phase locking (penguncian fasa). Gambar 7(b) setelah dilakukan phase locking (penguncian fasa), pada gambar ini $\omega_{i n j}$ sedikit lebih lebar dari sebelumnya. Karena jika $\omega_{i n j}$ bergerak keatas $\omega_{0}$, maka sideband kanan akan menjadi semakin besar. Selain itu menyatakan bahwa sisa spectrum akan simetris meski terjadi 
pengisian arus yang sangat kecil, tetapi sideband akan bertambah jumlah dan pada nilai magnitude.

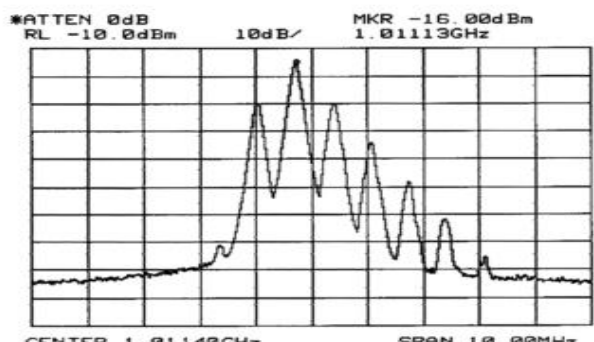

(a)

Gambar 7(a). sebelum dilakukan phase locking (penguncian fasa) [14]

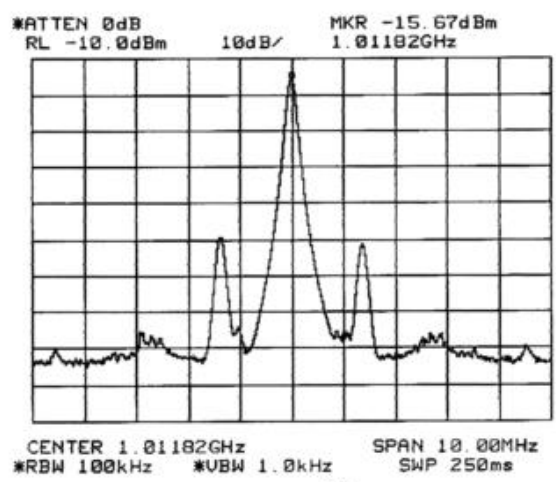

Gambar 7(b). setelah dilakukan phase locking [14]

Injection-locked dikembangkan untuk memperkuat frekuensi gelombang milimeter upconverted [15].Guna meningkatkan efisiensi injeksi dan jangkauan penguncian untuk pembagian frekuensi superharmonic [16]. Injection locking digunakan memngurangi derau fasa pada osilator [10], [12], [14]-[21]. [22]

\section{Kesimpulan}

Kajian ini memberikan gambaran bahwa salah asatu cara yang sering digunakan untuk mengurangi derau fasa pada osilator cincin (Ring Osilator) adalah dengan cara suntikan penguncian (injection locking).

Telah dibuktikan pada [10], [12], [14]-[21] telah diujicobakan bahwa injection locking adalah salah satu cara untuk mengurangi derau fasa. Tetapi banyak cara lain yang bisa mengurangi derau fasa contohnya membuat keluaran quadrature, dan semua diaplikasikan sesuai kebutuhan dari osilator.

\section{Daftar Pustaka}

M. S. Asghar, “Institutionen för systemteknik Department of Electrical Engineering," 2012.

J. Bank, A Harmonic-Oscillator Design Methodology Based on Describing Functions. 2006.

[3] W. M. Chun, "Inductor-less Frequency Synthesizer for Bluetooth Application By," 2002.

[4] D. S. Douglas, “Cmos Ic o," 2008.

[5] C. D. Group, "Design of CMOS ring oscillator," vol. 1, no. 95, pp. 1-95, 2005.

[6] G. Guo, "Oscillators with Constant Frequency over," 2012.

[7] D. Murugan, “Institutionen för systemteknik Design of a Voltage Controlled Oscillator for Galileo / GPS Receiver," 2012.

[8] H. J. (concordia university) Yao, "S2 Low Phase Noise VCO.pdf." 2006.

[9] P. Nugroho, "Rangkaian Osilator Cincin dengan Sinyal Keluaran Quadrature untuk Aplikasi Komunikasi Nirkabel," vol. 1, no. 2, 2012.

[10] R. Melville, D. Long, V. Gopinathan, and P. Kinget, "An Injection Locking Scheme for Precision Quadrature Generation."

[11] B. Razavi, "Book-Design-of-Analog-CMOSIntegrated-Circuits-Behzad-Razavimarcado.pdf." Los Angeles, 2001.

[12] R. Dehghani and S. M. Atarodi, "A Low Power Wideband 2.6GHz CMOS Injection-Locked Ring Oscillator Prescaler," pp. 6-9, 2003.

[13] B. Razavi, "A Study of Phase Noise in CMOS Oscillators," vol. 31, no. 3, pp. 331-343, 1996.

[14] B. Razavi, "A Study of Injection Locking and Pulling in Oscillators," vol. 39, no. 9, pp. 14151424, 2004.

[15] M. M. Gourary, S. G. Rusakov, S. L. Ulyanov, M. M. Zharov, B. J. Mulvaney, and K. K. Gullapalli, 
"Analysis of Oscillator Injection Locking by Harmonic Balance Method," pp. 318-323, 2008.

[16] R. Oscillators, W. M. Injection, J. Chien, S. Member, and L. Lu, "Analysis and Design of Wideband Injection-Locked," vol. 42, no. 9, pp. 1906-1915, 2007.

[17] M. K. Kazimierczuk, V. G. Krizhanovski, S. Member, J. V Rassokhina, and D. V Chernov, “Injection-Locked Class-E Oscillator," vol. 53, no. 6, pp. 1214-1222, 2006.

[18] J. Lee and H. Wang, "Study of Subharmonically Injection-Locked PLLs," vol. 44, no. 5, pp. 1539-1553, 2009.

[19] F. Ramírez, M. Pontón, and S. Sancho, "PhaseNoise Analysis of Injection-Locked Oscillators and Analog Frequency Dividers," vol. 56, no. 2, pp. 393-407, 2008.

[20] H. R. Rategh, S. Member, and T. H. Lee, "Superharmonic Injection-Locked Frequency Dividers," vol. 34, no. 6, pp. 813-821, 1999.

[21] M. Waves, "INJECTION LOCKED MILLIMETER WAVE OSCILLATORS AT Ka, V, AND W-BANDS S. Ramakrishnan and S. S. Sarin," vol. 20, no. 3 , pp. 453-459, 1998.

[22] I. T. Ag and Ó. Đ. Đ. Ø. Ó. Ö. Ø. Ý, “A $50 \mathrm{GHz}$ direct injection locked oscillator topology as low power frequency divider in $0.13 \mu \mathrm{m}$ CMOS," pp. 1-4. 